Cole, Laura and Drennan, Vari (2019) Living with incontinence : the experience of people with dementia. Dementia, 18(5), pp. 1826-1839. Copyright (C) 2019 SAGE Publications. DOI: 10.1177/1471301217731171 


\title{
Living with incontinence: the experience of people with
}

\section{dementia}

\author{
Laura Cole ${ }^{1}$ and Vari M. Drennan $\mathrm{MBE}^{2}$
}

${ }^{1}$ Social Care Workforce Research Unit, King's College London, UK

${ }^{2}$ Centre for Health and Social Care Research, Joint Faculty of Kingston University \& St

George's, University of London, UK

\section{Corresponding author:}

Laura Cole, Social Care Workforce Research Unit, King's College London, Strand, London, UK.

Email: laura.cole@kcl.ac.uk 


\title{
Living with incontinence: the experience of people with
}

\section{dementia}

\begin{abstract}
Dementia is a distressing condition in which individuals progressively require the support of others. Many people experience problems with incontinence and continence management. The presence of incontinence is influential in decisions for people with dementia to move into a care home. This study, in the interpretative tradition, investigates for the first time the person with dementia's perspective on these problems and their strategies for managing them. We conducted semi-structured conversational interviews with seven people with mild to moderate dementia and analysed the transcripts thematically. Our participants described both a variety of problems with incontinence and continence management, and their embarrassment and humiliation. Strategies included managing their presentation of self to others to keep such problems hidden, although it was evident that for some their cognitive problems led to strategies that were potentially problematic for others. In addition, some described the ways in which they acted to protect others, such as spouses, from the stigmatising effect of the incontinence.
\end{abstract}

\section{Keywords}

Dementia; incontinence; older people; qualitative; stigma. 


\section{Background}

Dementias are progressive conditions that interfere significantly with a person's ability to maintain the activities of daily living. It affects the person, their family and has consequences for the wider community. The numbers of people with dementia are projected to rise internationally with the aging of populations (Prince et al. 2015). The World Health Organisation (WHO) has called for member nations' to take public health action on prevention, awareness and care (WHO, 2016b). One aspect of national strategies in high income countries is to support people with dementia, and their family carers to remain in their own homes for as long as possible, rather than moving to a care home (European Parliament, 2010; Congress of United States of America, 2010). However, evidence suggests that incontinence i.e. the leakage of urine or faeces (Abrams, Cardozo, Khoury, \& Wein, 2013) contributes to the overburdening of family carers and is a significant factor in the decision for people with dementia to move into a long-term care placement (Luppa, Luck, Braehler, Koenig, \& Riedek-Hellier, 2008; Young, Kalamaras, Kelly, \& Hornick, 2015). It is therefore an important but often hidden issue.

Dementia is a syndrome in which there is progressive loss of cognitive and latterly physical functioning (WHO, 2016a) and it is often accompanied by deterioration in social behaviour, emotional control and motivation (American Psychiatric Association, 2007). One aspect of dementia is the loss of independence in basic activities of daily living such as maintaining personal hygiene and managing personal care (Reisberg, Ferris, de Leon, \& Crook, 1982), which includes using the toilet and managing incontinence. The progressive nature of dementia can affect the ability to remain continent in a number of ways. The loss of cognitive abilities has possible ensuing problems of disorientation, lack of concentration and apraxia, affecting the person's ability to recognise the urge to use the toilet, locate the toilet, manage 
their clothes, and void appropriately (Stokes, 1995; Stokes, 2000). Behavioural and psychological symptoms of dementia can impact negatively on voiding behaviours (Stokes, 1995; Stokes, 2000). Any of these can result in the person with dementia experiencing difficulties with using the toilet, remaining continent and/or managing incontinence.

Incontinence is known to be experienced by adults as humiliating and embarrassing (Abrams et al. 2013). The prevalence of urinary incontinence in older adults living in the community is between two and 15 percent, and three to 17 per cent for faecal incontinence; but underreporting is known to be widespread (Milson et al. 2009). Using general practice records in the United Kingdom (UK), Grant and colleagues (2013) found that the rates of first diagnosis of urinary incontinence for people with dementia living at home were double, and faecal incontinence triple, those for people without a dementia (Grant, Drennan, Rait, Peterson, \& Iliffe, 2013). While incontinence is known to be a significant factor in the decision for people with dementia to move residence to a care home (Caldwell, Low, \& Brodaty, 2014; Luppa et al. 2008; Young et al. 2015), it is not known what aspects of the incontinence (e.g. whether it is faecal or urinary, or associated with management problems) specifically contribute to the decision making.

Investigations into continence management strategies invariably come from the perspective of professionals and most focus on care home settings (Wagg et al. 2013). A handful of studies have investigated the experience of managing such problems from the perspective of family carers (Drennan, Cole, \& Iliffe, 2011; Forbat, 2004; Cassels, \& Watt, 2003). These studies identified some coping and management strategies that either privileged the person with dementia's interests before the carer's (e.g. protecting the person's dignity by not seeking professional help, Drennan et al. 2011), or were likely to be counterproductive for the 
person with dementia (e.g. limiting activities outside of the home, or restricting fluid intake later in the day to avoid the need to urinate at night, Drennan et al. 2011; Cassels, \& Watt, 2003; Forbat, 2004). Only in recent years has some attention be given to advising family carers on evidence based strategies (Alzheimer's Europe, 2014). While there are some insights into the experience from the carer's perspective there is little from the perspective of the person with dementia living at home with these types of problems.

This paper reports on a qualitative study that aimed to investigate the experiences of people with dementia who had incontinence problems including difficulties with using the toilet. It was nested within a wider group of studies, aimed at exploring and addressing issues in primary care settings for people with dementia and their carers (Iliffe et al. 2015).

\section{Theoretical Framework}

The methodology of the study drew on the interpretative tradition taking both an inductive and deductive approach (Crotty, 1998). Based on the wider literature, candidate theoretical framing drew on theories of stigma (Goffman, 1963) which are acknowledged to apply both to the condition of dementia and to adult incontinence in all societies (we outline further below). At the same time a "bottom up" approach was also taken to capture the lived experience of the individuals and not limit the investigation to aspects only related to stigma.

The sociologist Ervine Goffman first proposed the theory of stigma as applied to socially discreditable characteristics that mark an individual as negatively different in some way to others in society (Goffman, 1963, p. 14). Stigmas are "socially constructed in and through social relationships" (Pescosolido, Martin, Lang, \& Olafsdottir, 2008, p. 432) and do not just include individual or psychological factors but also incorporate societal factors such as the 
community and the media. Stigma is important because the social discrimination is accompanied by a "power differential" (Benbow, \& Jolley, 2012, p. 3) which undermines an individual's personhood, quality of life and well-being (Milne, 2010). Stigma can result in internalisation of the stigma (Stuber, Meyer, \& Link, 2008). Self-stigmatization can lead to disengagement from society, and the person feeling worthlessness, invisible, and ashamed (Milne, 2010). The effects of stigma can be so strong that the anticipation of being treated differently (negatively) by others without the illness, can cause psychological stress even when no discrimination may even be present or experienced (Stuber et al. 2008).

Dementia is a stigmatised condition (Batsch, \& Mittleman, 2012). While there are active steps in many societies to change perceptions of dementia, such as through national dementia strategies (e.g. in the UK: Department of Health, 2009; Department of Health, Social Services and Public Safety, 2011; Scottish Government, 2013; Welsh Assembly Government, 2011), it is known that perceived stigma shapes the behaviours of people with dementia and their family members. Fear of being labelled has serious health consequences as individuals reduce their social interactions (Langdon, Eagle, \& Warner, 2007), delay or avoid seeking treatment and support (e.g. Iliffe, Walters, \& Rait, 2000), or become noncompliant with treatment (Link \& Phelan, 2006).

For people with dementia with incontinence, there is a doubling of stigmas, as incontinence is also a stigmatised health condition (Bamford, Holley-Moore, \& Watson, 2014; Benbow, \& Jolley, 2012; and Drennan et al. 2011). Consequently, there is a potential intersection of stigmas; experiencing incontinence problems and having a dementia diagnosis. The "intersection of multiple sources of stigma and prejudice" is a health area often overlooked in 
research, and is of interest to us to understand how these intersections may affect health (Stuber et al. 2008, pg. 352).

\section{Methods}

This qualitative study was in the interpretative tradition (Crotty, 1998). The research design was of guided conversations rather than semi-structured interviews, a technique recommended by Murphy (2007) when_involving people with dementia in research. Guided conversations are used to gain the views and experiences of people with dementia without the reliance of factual recall. The researcher uses an aide memoire of the topic areas of interest to help shape the conversation, but the style remains fluid and informal (Murphy, 2007). Areas explored were: the types of problems related to using the toilet, experiences of incontinent episodes, how they felt and managed these problems, and whether they discussed these issues with anyone (family and professionals).

The study aimed to recruit ten people with mild to moderate dementia (Reisberg et al. 1982) living at home with incontinence or problems with using the toilet. Within the sample the aim was to have diversity in gender, living alone or with others, ethnicity, and socio-demographic circumstances. Recruitment was conducted alongside a study investigating family carer perceptions of supporting a person with dementia experiencing incontinence in an English city (Iliffe et al. 2015). Multiple routes were used to approach potential participants. This included through voluntary organisations, family carer meetings, health and social care organisations providing specialist services to community dwelling people with dementia and their families, and eight general practices. Initial written information about the study invited those interested to contact the researchers for further information at a pre-arranged meeting of a time and place of their choosing. Invariably these arrangements were made by the family 
carer or a professional on the person with dementia's behalf. At this meeting, the researcher described the study, provided written information and judged capacity to consent as guided by the Mental Capacity Act 2005. All participants had to be able to understand, retain, and ask questions about the research study. Their participation was voluntary and they were free to withdraw at any point up to the completion of the study. While the researchers confirmed that all information would be reported anonymously, it was made clear to all potential participants and their supporters that if any information shared suggested a vulnerable adult was at risk of neglect, harm or abuse then the researchers would be required to alert either the referring professional or the appropriate authority under the local safeguarding adults policies (Association of Directors of Social Services, 2005). Prior consideration was also given by the researchers as to actions to take should an individual or their family member become distressed.

The guided conversations all took place in the person's home and, with permission, were digitally recorded. Field notes were written immediately after the interview to assist in recording any non-verbal or contextual data that would aid interpretation of the verbal data (Silverman, 2010). The recordings were later transcribed verbatim, and thematically analysed (Boyatzis, 1998), with the aid of NVivo software (QSR, 2008). Transcripts were read multiple times and coded line-by line. Reoccurring patterns were identified by the two authors independently at first. Patterns in the data were then compared and contrasted across the data until broader themes were generated and agreed by both authors, resolving any disagreement through discussion.

The study was favourably reviewed by a NHS local Research Ethics Committee with a specific remit for people with mental health problems and vulnerabilities. Formal research 
governance permissions were also obtained in seven NHS Primary Care Trusts, a Mental Health Trust providing older peoples services in five local authorities, one Adult Social Services department, and a specialist dementia housing association.

Eighty-nine people with dementia and their family carers were provided with information about the study by the research team. Eventually over a period of 12 months, seven people with mild to moderate dementia and incontinence problems agreed to participate in the study. Five participants were recruited via introductions from community mental health services and two via approaches from their general practitioners. None of the participants were recruited through voluntary sector organisations or services providing social care. Five participants signed a consent form, and two participants gave their verbal consent, in the presence of their supporter (e.g. family carer), agreeing their participation. We considered that the small sample might be due to the intersection of stigmas attached to both dementia and incontinence, and the group being 'hard to reach', not always in receipt of health or support services.

Seven people with dementia participated: four on their own and three people either gave their accounts in the presence of a supporter or as part of a joint family interview. Table 1 provides brief details of the demographic characteristics of the participants.

The guided conversations allowed participants to clearly convey problems that they were experiencing and how they coped. Most had some word-find difficulties but this was usually remedied through word substitution or asking for the assistance from the researcher or their supporter. Participants were relaxed and did not appear to be embarrassed about discussing their difficulties with using the toilet and incontinence problems with the researcher. The 
most difficult aspect of the interview was balancing participants' need to rely on their supporter's for forgotten details, with ensuring the supporter did not continue answering questions, thereby monopolising the interview. The researcher worked hard to ensure that participants were given a 'voice' throughout the interview and that their experiences and perspectives were expressed and not those of the supporter. This was achieved by interviewing the person with dementia alone where possible, and only calling supporters' assistance when the person with dementia needed support with wording find, or clarification of an event.

\section{Findings}

During the process of analysis, the researcher identified three themes: 1) the type of difficulties experienced and associated feelings, 2) strategies to manage difficulties with using the toilet and incontinence, and 3) help in managing incontinence. These are now described.

\section{Types of difficulties experienced and associated feelings}

Participants used colloquial and often polite terms for the toilet, urinating and defaecating, such as "wanting to go", "bedwetting", "loos", "other side of the job" (referring to defaecation). They reported a range of incontinence problems or difficulties when using the toilet (summarised in Table 1). Most participants described a single problem, the majority experiencing urinary incontinence. However, some participants described more than one type of problem. One participant experienced difficulties with sequencing to use the toilet and urinary incontinence. He described the urgency in needing to urinate once the sensation was recognised: 
“. . . and I now find that I can't hold it physically and it does start and that is really hard from the point of view of making sure I'm near a loo because when I want to go, I want to go quickly and that's really the problem on incontinence" (man living with wife, 04).

Another participant reported having problems with his bladder and bowel. In this exemplar, he describes his experience of faecal incontinence:

"Bowel problems, I have one or two bouts of diarrhoea but that seems to have disappeared now. I may be exaggerating, it may come back for all I know, because I don't know, I don't think so" (man living alone, 05).

Participants indicated that being continent was their preferred state, as in this exemplar:

"I think it's fair to say that I have been free from bedwetting, probably two weeks, maybe more. Which is nice, believe me (slight laugh)" (man living alone, 05).

All the participants reported their problems with using the toilet and incontinence in negative and burdensome terms:

"I wouldn't wish it on anyone" (women living alone, 01).

“. . .this perishing intrusion (the urgency to urinate and incontinence)" (man living with wife, 03).

Participants also conveyed their embarrassment and shame at these experiences using words such as "mortified":

[Following an episode of urinating while in bed] "It's like a fire really, I mean with everything, we [he and his wife] have to get up, change the sheets, I'd be mortified you know and all that" (man living with wife, 04). 
Those participants experiencing only urinary incontinence expressed their relief and thankfulness of not having faecal incontinence. To lose control of one's bowels seemed to be viewed as much worse than urinary incontinence:

“I don't, that's one thing, no, no, no, oh God, oh no, I wouldn't like that, I think that's terrible.... No, thank God I don't, I'm ever so pleased"' (women living alone, 02).

"We don't have, so far we don't have any problems with the other toilet, the other side of the job.... We don't seem to have that yet, so" (man living with wife, 03).

\section{Strategies to manage difficulties with using the toilet and incontinence}

\section{problems}

Participants described a range of strategies they used to manage continence and minimise the problems they experienced when using the toilet. Some of these were precautionary and preventative actions. One common strategy was to plan trips outside of the home based on the location of public toilets, a form of 'toilet mapping':

"Yeh I take precautions and making sure when I set off, set off from here, I make sure which, which route I can take [where there are public toilets]" (man living with wife, $03)$.

Another preventative action was to restrict fluid intake in the evening to reduce the need to urinate and prevent nocturnal enuresis ("bedwetting"):

"I limit the amount of drink towards the end of the day and that works" (man living alone, 05). 
Strategies to ensuring minimal urine spillage and containment of excreta were also described in the conversations. Examples were given of changes in approaches to preparing to use and using the toilet. One man described sitting rather than standing to urinate to avoid spillage. Another strategy was for a family carer to assist in the process of using the toilet. In this example the person is describing how his wife helps with his clothing and position him on the toilet, and the difficulties he experiences:

"Yeh most of the time I feel confident that, what part [wife's name] plays and what part. They come together and that's that. But there are occasions when it's touch and go whether, you can sort of be, sort of be prepared for it but you haven't actioned it yet" (man living with wife, 03).

This participant also described how managing the process of undressing and using the toilet became more difficult when he was tired, for whatever reason, and then he needed even more assistance.

Containing excreta was viewed as important and strategies to prevent urine spillage or faecal leakage were described by many participants, although these were not always successful. Night time was described as one which required a number of precautionary strategies. Two people described sleeping on towels to catch any urine leakage at night:

"I have an old towel that nobody would, if they've got any sense, because it does go to the wash.... Well I can pour like a tap or I can, don't run at all' (women living with husband, 07).

Four of the seven participants interviewed were using incontinence pads as the mechanism for containment of excreta. The source and funding of these varied. One participant bought their pads privately and another had been given pads at a hospital discharge. Two people 
received incontinence pads through the local community National Health Service (NHS). For some participants receiving NHS funded pads there were issues regarding adequacy and acceptability of those provided. This exemplar describes the process one participant used to make the pads smaller and thus acceptable:

"I'm so small you know, and I've been cutting them and the whole flat is covered in bits of, what do you call it, small pieces, fluff, every day fluff...they're so big, I've got to cut the .... I mean I feel they take over my whole body, they don't but I just get that feeling" (woman living alone, 01).

Acceptability of size and fit was reported as important. This participant described her satisfaction with her current type of NHS supplied incontinence pads compared to a previously provided design:

"Oh they're good they [the incontinence pads] are, they're very nice because they're just nice and small, they're not big, big ones like the other ones I had, these are smaller ones" (women living alone, 02).

\section{Help in managing incontinence}

All seven people with dementia reported the involvement of health care professionals in their care. Due to their difficulties in recall, it was not possible to ascertain from all participant accounts whether they had received a full assessment of their incontinence problems or difficulties with using the toilet, although some had received or were awaiting active intervention. Two people described their General Practitioner's involvement and examinations. Two described an impending or a recent surgical procedure that they hoped in time would have a positive effect on their incontinence. 
One person with dementia talked of assistance from an occupational therapist who had provided grab bars by the toilet and a step to get into the bath. Two people living alone with dementia had District Nurses visiting daily to administer medication, assist with other health problems, and for monitoring. Most recounted their experiences with health professionals regarding these problems in a positive tone. However, one participant described her own frustration and the negative response received from a hospital doctor when she experienced difficulty with following instructions to give a urine sample. The negative interaction led to her not following through on having her problems thoroughly investigated:

"I couldn't even give her a quarter of what she wanted and then I would come out of the hospital place and I'd be wet but you know, to give on tap... I couldn't do it, I went there three times and if I can't give her a decent sample she doesn't want to know and I just gave up" (woman living alone, 01).

In some of the narratives it became apparent that managing incontinence and preventing leakage could be a source of difference of opinion and tension. In this example, the person with dementia tries to assert her right to continue taking laxatives, despite her husband and son stating that she now takes too many which caused 'accidents' or faecal leakage.

Person with dementia: "Look, I take what I need, I don't take too much, so ...."

Son: "Mother! You take more than you need".

Husband: "You should take only two a day, it's on the, on the box".

Person with dementia: "Mm, that I know" (woman living with her husband, 06).

Other people with dementia did not want help with managing their incontinence, not due to family tension but as they considered their family member's feelings, wishing to protect them from having to deal with any excreta. This was mixed with feelings of embarrassment and not 
wanting to disclose the incontinence. However, the accounts the participants gave of actions and decisions they made, with this motivation but without an understanding of the consequences, appeared likely to cause other types of problems or sources of tension such as offensive odour, as in this example:

"There's always the fear and sometimes I don't get there it time and I find myself with wet pyjamas and it's personally very embarrassing. My wife is understanding about it and I try and not do that and you know keep as much as I can from her out of pure respect for her, you know cos it will dry off as these things do" (man living with wife, 04).

\section{Discussion}

This paper describes the views and experiences of people with mild to moderate dementia who have problems with incontinence and using the toilet; and to the best of our knowledge is the first paper to do so. The problems they describe are a result of the interplay between the severity of the individual's cognitive problems, the person's physical disabilities, the level of support received, and the aetiology of specific incontinence problems.

Like adults in other studies of incontinence (Cotterill, Norton, Avery, Abrams, \& Donovan, 2008; Olsson \& Berterö, 2014), people with dementia in our study described feelings of embarrassment and shame. Faecal incontinence was considered worse than urinary incontinence. While the participants were not able or willing to explain why, one explanation could be that individuals were exerting self autonomy in self-management, but another is that our data seems to relate to human responses to excreta. The anthropologist Mary Douglas argued in her seminal study that faeces and defaecation are linked with danger, defilement, taboo and pollution across cultures (Douglas, 1966). Subsequent researchers in this little 
studied aspect of human responses to faeces and urine have suggested that disgust at the sight or smell of excreta is a powerful emotion and an evolved physical defence (Curtis, Voncken \& Singh, 1999).

Strategies were those of prevention, adaption, coping and containing excreta. Some of these led to curtailments, such as trips outside the home were limited to those where there was known access to toilet; which has been reported previously by those with continence problems but without dementia (Cotterill, Norton, Avery, Abrams, \& Donovan, 2008). Some of these strategies also had the potential for negative effects, such as limiting fluid intake, which increases the risk of dehydration and urinary infections (Wagg et al. 2013), and have been reported before from the family carer perspectives (Drennan et al. 2011). For those living with family members, using the toilet meant using adaptations and relying on significant input from those family members which has been previously described from the family carer perspective (Forbat, 2004; Cassels, \& Watt, 2003). Surveys of family carers of people with dementia have reported incontinence as one of the most problematic symptoms to manage (Georges et al. 2008).

Some insight is given here into the potential relationship tensions different aspects of incontinence can create between the person with dementia and their family members. We offer for the first time the insight that the person with dementia may at times be acting in ways to protect family members from having to deal with excreta "out of place" and the potentially polluting effect (Douglas, 1966, p.44). Participants described how they made efforts to change their behaviours to minimise their family member's exposure to their incontinence problems. This coupled with their own feelings of embarrassment and shame, suggest that people with dementia were protecting their families from the 'secondary' effects 
of stigma. This accords with Goffman's (1963) theory, that those who provide intimate care receive a "courtesy stigma" (Goffman, 1963, p. 44), as they are viewed in a similar way and "obliged to share some of the discredit of the stigmatized person to whom they are related" (Goffman, 1963, p. 43). Also referred to as a "secondary stigma" (Milne, 2010, p. 228) or 'stigma by association' (Werner \& Heinik, 2008). The impact that dementia and incontinence has on relationships should not be underestimated or assumed and requires further investigation (Cole, 2015).

It was apparent that containment of excreta as far as possible was important, explainable both practically in terms of the work it created but also in terms of minimising pollution to others (Douglas, 1966; Curtis et al. 1999; Curtis \& Biran, 2001) with the associated stigma (Goffman, 1963). Most of the participants were using some form of absorbent containment whether it was towels or continence pads (known as diapers in many countries). The extent to which these participants had asked for health service provision of continence pads is unknown but variable quality of continence care has been reported before (Wagg, Harari, Husk, Lowe \& Lourtie, 2010). Those that were receiving National Health Service (NHS) funded pads reported issues in acceptability and usability in the types and design they were offered, an issue that has been raised from the family carer perspectives (Drennan et al. 2011). The extent to which health professionals were involved in helping address the problems of using the toilet and managing continence was hard to gauge from this type of study. However the reported instance of challenges faced by the person with dementia managing the requests of a secondary care service investigating her incontinence problems perhaps gives insights into the need for more dementia awareness in non-dementia services, a point raised both in national strategies (Department of Health, 2009; Department of Health, 
Social Services and Public Safety, 2011; Scottish Government, 2013; Welsh Assembly Government, 2011) and international strategies (WHO, 2016b).

As a qualitative study we have offered insights and explanations of individual behaviours which relate to theories of stigma and protection from courtesy stigma. The insights offered here may be of value to family members, and health and social care professionals in their interactions with people with dementia and the management of incontinence. Some require further application and testing, as well as informing educational programmes. In this, we illuminate further aspects to be considered alongside practical guidance offered by a range of organisations (for example Alzheimer's Europe, 2014).

\section{Limitations and Strengths}

The study had limitations but also strengths. The numbers recruited to participate were very small despite prolonged efforts via multiple routes. Our explanation of the difficulty for this lies in the double impact of stigma associated with both dementia and incontinence. We consider the relevance of multiple stigmas affecting the recruitment process to be an important finding and of value to others trying to investigate or test practical improvements in incontinence management with this population.

While the number of participants was small, there was diversity in their experience as planned in the design, of varying degrees of cognitive abilities within the range of mild to moderate dementia, and a range of different types of incontinence problems. Those who did take part in the research were able to reflect back on their earlier experiences, along with their anticipations and fears for the future when managing their continence whilst their dementia 
progresses over time. This diversity has added to the richness of the data and confidence in the insights offered here.

\section{Conclusion}

The perspective of the person with dementia has not been reported before in relation to using the toilet and incontinence problems. This study provides insights from the lived experiences of people with dementia as to how the feelings of shame influence their behaviours as well as how they develop strategies and adapt to assistance in managing continence. Concealing leakage and containment of excreta was found to be a mechanism for keeping their self respect and identity intact, but it was also undertaken from the desire to prevent family carers having to deal with excreta, which in turn may bestow upon them a courtesy stigma. Health and social care professional should be mindful that managing incontinence is not just a practical issue but also an emotional and psychological one. 


\section{Disclaimer}

This article presents independent research commissioned by the National Institute for Health Research (NIHR) under its Programme Grants for Applied Research scheme (RP-PG-06061005). The views expressed in this publication are those of the author(s) and not necessarily those of the NHS, the NIHR or the Department of Health.

\section{Declaration of conflicting interests}

None declared. 


\section{References}

Abrams, P., Cardozo, L., Khoury, S. \& Wein, A. (2013). Incontinence; $5^{\text {th }}$ International Consultation on Incontinence Paris, February 5-8. International Consultation on Urological diseases (ICUD), European Association of Urology (EAU). Retrieved from http://www.icud/incontinence.html

Alzheimer's Europe (2014). Improving continence care for people with dementia at home. Luxembourg: Alzheimer Europe.

American Psychiatric Association Work Group on Alzheimer's Disease and other Dementias, Rabins, P. V., Blacker, D., Rovner, B. W., Rummans, T., Schneider, L., . . Fochtmann, L. J. (2007). American Psychiatric Association practice guideline for the treatment of patients with Alzheimer's disease and other dementias ( $2^{\text {nd }}$ ed.). American Journal of Psychiatry, 164, (Suppl. 12), 5-56.

Association of Directors of Social Services, The. (2005). Safeguarding Adults: A National Framework for Standards for Good Practice and Outcomes in Adult Protection Work. London: The Association of Directors of Social Services.

Bamford, S., Holley-Moore, G., \& Watson, J. (2014). New perspectives and approaches to understanding dementia and stigma. London: International Longevity Centre-UK.

Batsch, N. L. \& Mittleman, M. S. (2012). World Alzheimer's Report 2012: Overcoming the stigma of dementia. London: Alzheimer's Disease International. 
Benbow, S. M., \& Jolley, D. (2012). Dementia: Stigma and its effects. Neurodegenerative Disease Management, 2(2), 165-172.

Boyatzis, R. E. (1998). Transforming qualitative information: thematic analysis and code development. London: Sage.

Caldwell, L., Low, L., \& Brodaty, H. (2014). Caregivers' experience of the decision-making process for placing a person with dementia into a nursing home: comparing caregivers from Chinese ethnic minoriyty with those from English-speaking backgrounds. International Psychogeriatrics, 26(3), 413-424.

doi:10.1017/S1041610213002020

Cassels, C., \& Watt, E. (2003). The impact of incontinence on older spousal caregivers. Journal of Advanced Nursing, 42(6), 607-16.

Cole, L. A. (2015). Exploring experiences of intimate toileting care and the impact on the family dyad relationship for people with dementia and their cohabiting family carer. Unpublished. London: St George's, University of London.

Congress of United States of America. (2010). National Alzheimer's Project Act S.3036. Retrieved from http://www.kintera.org/site/pp.asp?c=mmKXLbP8E\&b=5829219 
Cotterill, N., Norton, C., Avery, K. N., Abrams, P., \& Donovan, J. L. (2008). A patientcentered approach to developing a comprehensive symptom and quality of life assessment of anal incontinence. Diseases of the Colon \& Rectum, 51(1):82-87.

Crotty, M. (1998). The Foundations of Social Research. Sydney, Australia: Allen \& Unwin.

Curtis, V., \& Biran, A. (2001). Dirt, disgust, and disease. Perspectives in Biology and Medicine, 44(1), 17-31.

Curtis, V., Voncken, N., \& Singh, S. (1999). Dirt, and disgust: A Darwinian perspective on hygiene. Medische Anthropologie, 11(1), 143-158.

Department of Health. (2009). Living well with dementia: A National Dementia Strategy. London: Department of Health.

Department of Health, Social Services and Public Safety. (2011). Improving dementia services in Northern Ireland: A Region Strategy. Belfast: Department of Social Services and Public Safety.

Drennan, V., Cole, L., \& Iliffe, S. (2011). A taboo within a stigma? A qualitative study of managing incontinence with people with dementia living at home. BMC Geriatrics, 11(1), 17.

Douglas, M. (1966). Purity and Danger. London: Routledge. 
European Parliament. (2010). European initiative on Alzheimer's disease and other dementias. Retrieved from

http://www.europarl.europa.eu/oeil/FindByProcnum.do?lang=en\&procnum=INI/2010/2084

Forbat, L. 2004. Listening to carers talking about the subjects of continence and toileting. Nursing Times, 100(2), 46-49.

Georges, J., Jansen, S., Jackson, J., Mayrieux, A., Sadowska, A., \& Slemes, M. (2008). Alzheimer's disease in real life - the dementia carer's survey. International Journal of geriatric Psychiatry, 23,546-551.

Goffman, E. (1963) Stigma. Notes on the Management of Spoiled Identity. Englewood Cliffs, New Jersey: Prentice-Hall.

Grant, R. L., Drennan, V. M., Rait, G., Peterson, I., \& Iliffe, S. (2013). First diagnosis and management of incontinence in older people with and without dementia in primary care: A cohort study using the health improvement network primary care Database. PLoS Medicine, 10(8), 1-8.

Iliffe, S., Walters, K., \& Rait, G. (2000). Shortcomings in the diagnosis and management of dementia in primary care: towards an educational strategy. Aging \& Mental Health, 4, 286291.

Iliffe, S., Wilcock, J., Drennan, V., Goodman, C., Griffin, M., Knapp, M., . . .Warner, J. (2015). Changing practice in dementia care in the community: developing and testing 
evidence-based interventions, from timely diagnosis to end of life (EVIDEM). Programme Grants for Applied Research, 3(3). Retrieved from https://dx.doi.org/10.3310/pgfar03030

Langdon, S. A., Eagle, A., \& Warner, J. (2007). Making sense of dementia in the social world: a qualitative study. Social Science \& Medicine, 64(4), 989-1000.

Link, B. G., \& Phelan, J. C. (2006). Stigma and its public health implications. Lancet, 367, 528-529.

Luppa, M., Luck, T., Braehler, E., Koenig, H. H., \& Riedek-Hellier, S. G. (2008). Prediction of institutionalisation in dementia - a systematic review. Dementia \& Geriatric Cognitive Disorders, 23(5), 546-551.

Mental Capacity Act (2005). The Stationery Office Limited. Retrieved from http://www.legislation.gov.uk/ukpga/2005/9/pdfs/ukpga_20050009_en.pdf

Milne, A. (2010). The 'D' word: Reflections on the relationship between stigma, discrimination and dementia. Journal of Mental Health, 19(3), 227-233.

Milson, I., Altman, D., Lapitan, M. C., Nelson, R., Sillen, U., \& Thom, D. (2009). Epidemiology of urinary (UI) and faecal (FI) incontinence and pelvic organ prolapsed (POP). In P. Abrams, L. Cardozo, S, Khoury, \& A. Wein. (Eds.), Incontinence; $4^{\text {th }}$ International Consultation on Incontinence Paris, June 5-8. Plymouth: Health Publication Ltd.. 
Murphy, C. (2007). User involvement in evaluations. In A. Innes, \& L. McCabe (Eds.), Evaluation in Dementia Care. London: Jessica Kingsley Publishers.

Pescosolido, B. A., Martin, J. K., Lang, A., \& Olafsdottir, S. (2008). Rethinking theoretical approaches to stigma: A framework integrating normative influences in stigma (FINIS). Social Science \& Medicine, 67, 431-440.

Prince, M., Wimo, A., Guerchet, M., Ali, G., Wu, Y., \& Prina, M. (2015). World Alzheimer's Report 2015: The Global Impact of Dementia. London: Alzheimer's Disease International.

Olsson, F., \& Berterö, C. (2014). Living with faecal incontinence: trying to control the daily life that is out of control. Journal of Clinical Nursing, 24, 141-150. Retrieved from http://dx.doi.org/10.1111/jocn.12617

QSR. (2008). NVivo qualitative data analysis software. Version 8. QSR International Pty. Ltd. .

Reisberg, B., Ferris, S. H., de Leon, M. J., \& Crook, T. (1982). The Global Deterioration Scale for assessment of primary degenerative dementia. The American Journal of Psychiatry, 139, 1136-1139.

Scottish Government. (2013). Scotland's National Dementia Strategy: 2013-16. Edinburgh: The Scottish Government.

Silverman, D. (2010). Doing Qualitative Research (4 ${ }^{\text {th }}$ ed.). London: Sage. 
Stokes, G. (1995). Incontinent or not? Don't label: describe and assess. Journal of Dementia Care, 3(1), 20-21.

Stokes, G. (2000). Challenging Behaviour in Dementia: A person-centred approach.

Bicester: Winslow Press.

Stuber, J., Meyer, I., \& Link, B. (2008). Stigma, prejudice, discrimination and health. Social Science \& Medicine, 67(3), 351-357.

Wagg, A., Chen, L. K., Kirchner-Hermanns, R., Kuchel, G. A., Johnson, T., Ostaszkiewicz, J., . .Szonyi, G. (2013). Incontinence in the frail elderly. In P. Abrams, L. Cardozo, S. Khoury, \& A. Wein, (Eds.), Incontinence; $5^{\text {th }}$ International Consultation on Incontinence Paris, February 2012. Retrieved from https://www.ics.org/Publications/ICI_5/INCONTINENCE.pdf

Wagg, A., Harari, D., Husk, J., Lowe, D. \& Lourtie, J. (2010). National Audit of Continence Care. London: Royal College of Physicians. Retrieved from https://www.rcplondon.ac.uk/projects/outputs/national-audit-continence-care-nacc

Welsh Assembly Government (2011). National Dementia Vision for Wales. Cardiff: Welsh Assembly Government.

Werner, P., \& Heinik, J. (2008). Stigma by association and Alzheimer's disease. Aging \& Mental Health, 12(1), 92-99. 
World Health Organisation. (2016a). International statistical classification of diseases and related health problems, $10^{\text {th }}$ Revision. Online version. Retrieved from:

http://apps.who.int/classification/icd10/browse/2016/en

World Health Organisation. (2016b). Draft global action plan on the public health response to dementia. Retrieved from: http://apps.who.int/gb/ebwha/pdf_files/WHA70/A70_28-

en.pdf?ua $=1$

Young, Y., Kalamaras, J., Kelly, L., \& Hornick, D. (2015). Is aging in place delaying nursing home admission? JAMDA, 16, 900.e1-900.e6. 
Table 1: Participants' Characteristics

\begin{tabular}{|c|c|c|c|c|c|}
\hline Characteristics & $\mathrm{N}=7$ & & & & \\
\hline Gender & 4 female & 3 male & - & - & - \\
\hline Age & $\begin{array}{l}2 \text { aged } \\
76-80 \text { years }\end{array}$ & $\begin{array}{l}3 \text { aged } \\
81-85 \text { years }\end{array}$ & $\begin{array}{l}2 \text { aged } \\
86-90 \text { years }\end{array}$ & - & - \\
\hline Ethnicity & 4 White British & 2 White Other & 1 White Irish & - & - \\
\hline Housing & 3 lived alone & 4 lived with spouse & - & - & - \\
\hline Type of care & $\begin{array}{l}1 \text { independent (no care } \\
\text { needed) }\end{array}$ & 2 family care & 3 formal (paid) care & $\begin{array}{l}1 \text { family \& formal } \\
\text { care }\end{array}$ & - \\
\hline $\begin{array}{l}\text { Continence } \\
\text { issue/s }\end{array}$ & $\begin{array}{l}4 \text { urinary incontinence } \\
\text { (UI) }\end{array}$ & $\begin{array}{l}1 \text { faecal incontinence } \\
\text { (FI) }\end{array}$ & $\begin{array}{l}1 \text { doubly (UI \& FI) } \\
\text { incontinent }\end{array}$ & $\begin{array}{l}1 \text { toilet difficulties } \\
\text { \& UI }\end{array}$ & \\
\hline Use of pads & 3 no pad worn & $\begin{array}{l}1 \text { pad worn only } \\
\text { when out }\end{array}$ & $\begin{array}{l}0 \text { pad worn only in the } \\
\text { day }\end{array}$ & $\begin{array}{l}1 \text { pad worn only at } \\
\text { night }\end{array}$ & $\begin{array}{l}2 \text { pad worn } \\
\text { night \& day }\end{array}$ \\
\hline
\end{tabular}

